ORIGINAL ARTICLE

\title{
Evaluation of undergraduate medical and dental students' perceptions and feedback of teaching learning methodology in pathology.
}

\author{
Nabeela Naeem 1 , Shahid Jamal ${ }^{2}$, Shameela Majeed ${ }^{3}$, Rabiah Asghar ${ }^{4}$, Haroon Khan ${ }^{5}$, Amat-ul-Naval Talha ${ }^{6}$
}

Article Citation: Naeem N, Jamal S, Majeed S, Asghar R, Khan H, Talha Amat-ul-Naval. Evaluation of undergraduate medical and dental students' perceptions and feedback of teaching learning methodology in pathology. Professional Med J 2022; 29(3):415-419.

https://doi.org/10.29309/TPMJ/2022.29.03.6186

ABSTRACT... Objectives: To determine frequency of students' perceptions (satisfaction) regarding teaching effectiveness, feedback of assessment mode and suggestions for improvement in pathology teaching technique in a medical college. Study Design: Cross-sectional Study. Setting: Medical \& Dental College Islamabad. Period: January 2017 to June 2017. Material \& Methods: A total of 224 students, who were going to appear for their professional examination were included in the study. Approval from the institutional ethical committee was taken. A set of questions on T/L practices and the suggested modifications were incorporated into the questionnaire. Descriptive statistics were used in the form of frequency distribution and data was analyzed by utilizing percentages. Results: Study demonstrated that female participants were more than male students. The subject of pathology was found to be interesting by majority of the students and it was consented that knowledge about pathology helps in clinical rotations. The subject of Pathology was expressed to be tough by about one third $(27.84 \%)$ of the students. Clinical correlations, presentations and explanations used to simplify the subject during lectures were found to be satisfactory by the students. Majority of the learners acknowledged that they were motivated to put up queries and respond to questions during lectures. Readability, usefulness of lecture presentations and innovative methods were thought to be acceptable by the students. Majority of the students recommended changes in teaching learning methods. Conclusion: A moderately high satisfaction was found among medical students regarding teaching and learning methodology of pathology. Pathology teaching system could be improved by applying group discussion; case based studies and integrated teaching approaches in our teaching system.

Key words: $\quad$ Assessment, Feedback, Perceptions, Pathology, Teaching Learning Methods.

\section{INTRODUCTION}

Effective medical learning is associated with high quality teaching in effective and proper environment. Efficient learning environment is a major challenge for delivering effective medical education. ${ }^{1}$ In recent years medical education has changed dramatically and several medical schools are trying to expand modern teaching techniques.

Pathology is the area of study in medicine that has a contribution in providing a scientific basis for medical practice. It is essential basic sciences subject in medical college and establishes the first foundation of knowledge regarding disease processes of human body. ${ }^{2}$ The perceptions of students can be used to assimilate a variety of constructive modes for explaining basic sciences related to clinical contexts. ${ }^{3}$ In order to reduce the extensiveness of facts required to be learned by medical students and load of didactic lectures in support of self-directed learning, most of the medical schools have reviewed and revised their curricula. In the revised curricula there is a progress of from being teacher-centered to student-centered, from discipline-based to mainly integrated teaching. Pathology museum sessions are being conducted that include slides demonstration not only by using microscopy but also PowerPoint show of images. With these changes, it is essential for Pathology teachers to adopt the modified method and assist in
1. MBBS, M Phil (Hematology), MHPE, Assistant Professor Pathology, Rawal Institute of Health Sciences Islamabad.

2. MBBS, MCPS, FCPS (Histopathology), Professor \& Head Pathology, Watim Medical \& Dental College Rawat.

3. MBBS, M.Phil (Chemical Pathology), Assistant Professor Pathology, Watim Medical \& Dental College Rawat.

4. MBBS, DCP, M.Phil (T), Clinical Pathologist, Excel Labs Islamabad.

5. MBBS, MSc Toxicology (Royal Post Graduate Medical School London), PhD Clinical Biochemistry (University of London), Chief Pathologist, Rawal Institute of Health Sciences, Islamabad.

6. MBBS, M.Phil (Hematology), Senior Lecturer Pathology, Watim Medical \& Dental College Rawat.

\author{
Correspondence Address: \\ Dr. Nabeela Naeem \\ Department of Pathology \\ Rawal Institute of Health Sciences Islamabad. \\ nabeelarizwan2207@gmail.com
}

Article received on:

$29 / 10 / 2020$ Accepted for publication:

$06 / 01 / 2021$ 
forming the courses with new approaches. ${ }^{4}$ The acceptability of these reforms by students can be revealed by their feedbacks that whether they have acquired adequate knowledge from pathology teaching that will be beneficial during their clinical rotations. Based on the suggestions of students' the teaching-learning of pathology can be improved by reviewing contents and teaching strategies. Therefore this research was directed to establish the students' feelings and response on effectiveness of pathology lecturing using a pre-validated questionnaire among students of a private medical college of Islamabad.

\section{MATERIAL \& METHODS}

This was a cross-sectional study based on questionnaire. Study duration was 06 months (January 2019 to June 2019). Students were approached through non probability consecutive sampling. Each student signed written consent before participation into study. Research ethical approval was taken from ethical review board (RIHS-REC/052/20). Inclusion criteria was based upon both genders, students of third year MBBS, fourth year MBBS and second year BDS. An exclusion criterion was based upon students who did not sign consent form and students of first year and second year. A structured questionnaire adopted from previous studies undertaken on the evaluation of teaching/learning in different disciplines was used for measuring satisfaction of students. The questionnaires were used as basis for developing our questionnaire that was suitably modified. Eighteen sets of questions related to teaching learning approaches and 05 related to amendments recommended were included in the questionnaire. Data was analyzed by utilizing descriptive statistics and results were expressed as percentages were used to communicate results.

\section{RESULTS}

A total of 224 students took part in the study and female predominance $(67.5 \%)$ was manifested by gender distribution.

\section{Subject Perception}

The subject of Pathology was recognized to be interesting by majority (64.42\%) of the students.
Similarly, it was found that $70.8 \%$ students were of the view that Pathology learning is of help in clinical trainings. Integration of pathology with clinical postings was felt helpful to apprehend the subject by $64.32 \%$ students. As regard to the perception that general pathology is a difficult subject, $38.53 \%$ of the students were neutral (Figure-1).

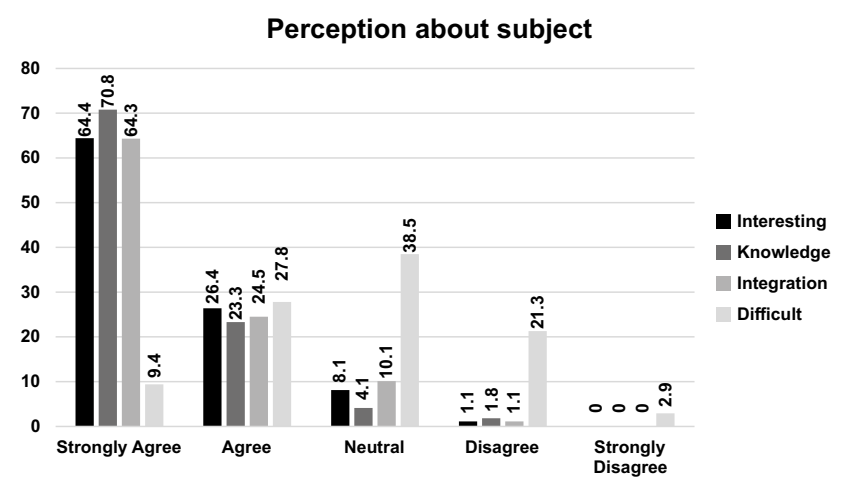

Figure-1. Perceptions about subject being interesting, knowledgeable, integrated and difficult.

\section{Teaching Methodology}

Content: The percentage of students who were contented with clinical correspondence and content of lectures was $48.42 \%$ and $42.46 \%$ respectively. $56.5 \%$ of the respondents opined that important points of subject were highlighted adequately while $52.5 \%$ students gave the impression that subject contents were effectively simplified through explanations (Figure-2).

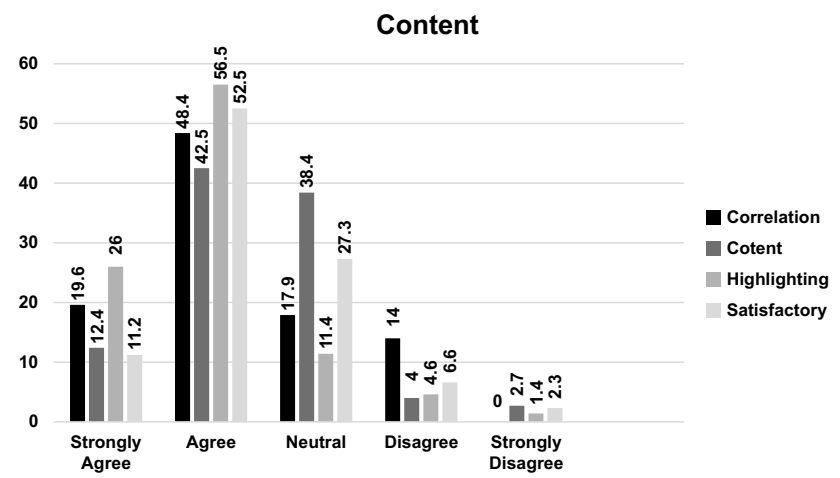

Figure-2. Clinical correlation, presentation of key points, adequacy and explanation of content.

Quality: $46.42 \%$ student consented that they were motivated to put up queries and respond to questions during lectures. Delivery and pace of lectures was found to be satisfactory by $41.84 \%$ of the students (Figure-3). 


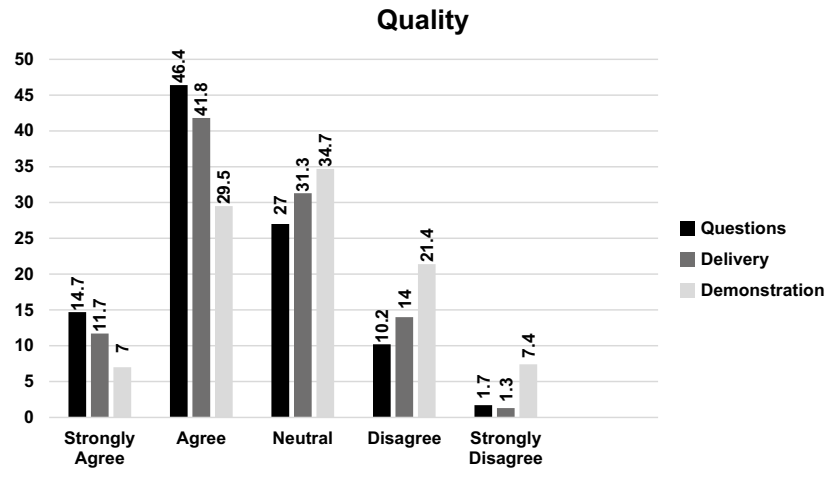

Figure-3. Lectures being interactive, well-delivered and understandable.

Teaching Tool: $54.62 \%$ students were satisfied as regard to the readability of lectures while usefulness of lecture presentation was felt sufficiently well by $52.54 \%$ students. Only $24.05 \%$ of the students were contented with the novel methods being pursued (Figure-4).

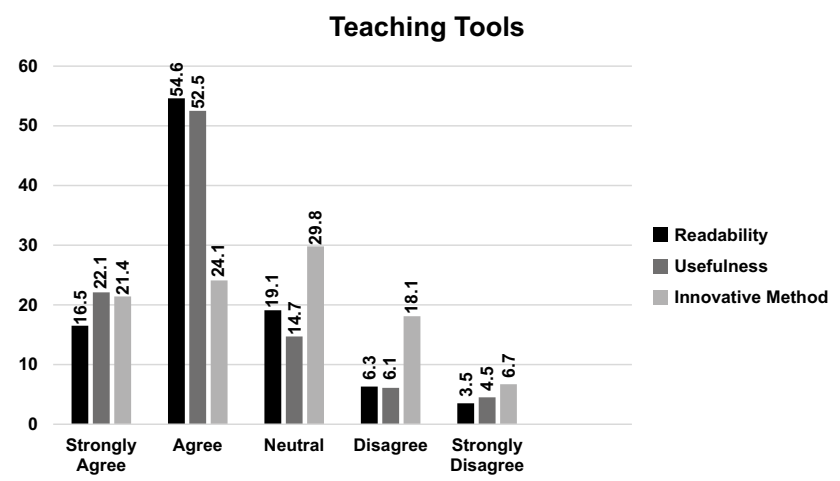

Figure-4. Usefulness and readability of presentations and use of innovative methods.

\section{Methods of Teaching}

Didactic lecture was agreed upon to be useful instructional approach by $44.92 \%$ students and $55.04 \%$ students felt power point presentation to be satisfactory (Figure-5).

\section{Changes Recommended}

The need for introduction of integrated teaching, case-based discussions and group discussions was felt firmly by majority (above $70 \%$ ) of the learners (Figure-6).

\section{Modes of Assessment}

$26.44 \%$ students strongly agreed that assessment should be conducted in form of written examination while viva voce examination was strongly favored by $23.52 \%$ of the students (Figure 07 ).

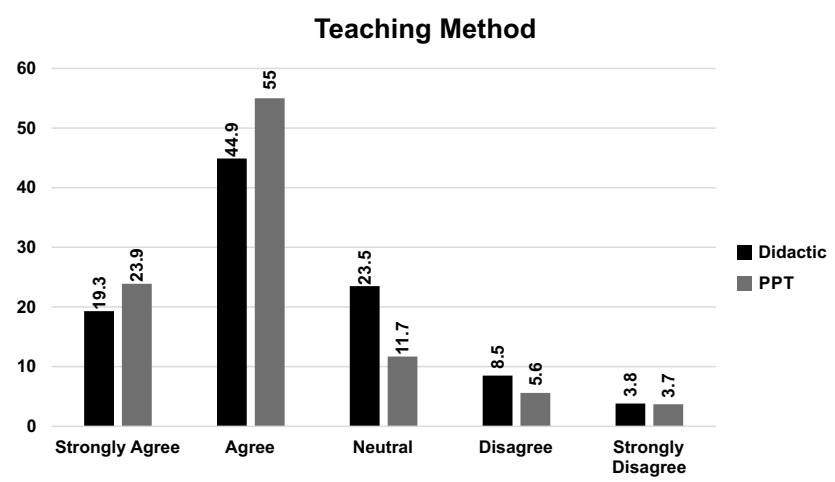

Figure-5. Methods of teaching consented by participants.

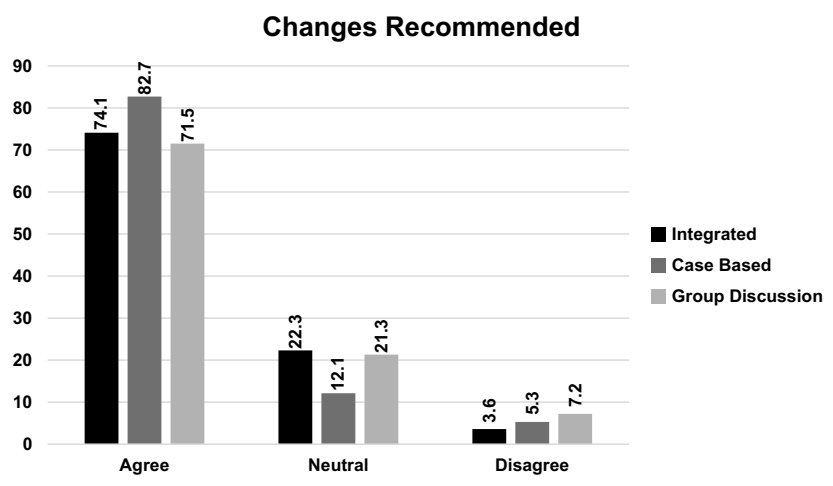

Figure-6. Changes recommended by participants.

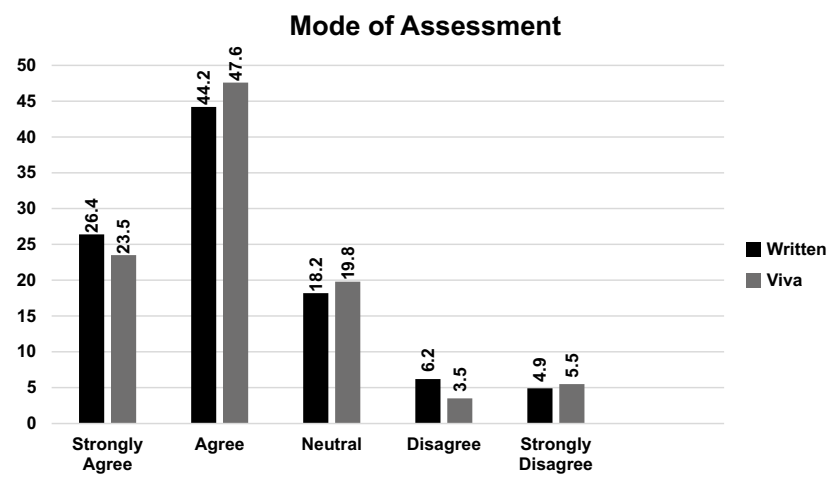

Figure-7. Modes of assessment agreed upon by participants.

\section{DISCUSSION}

It is generally agreed that teaching programs should be reviewed at regular intervals to bring modifications in teaching methods for imparting knowledge. In the current study, learners recommended that innovative teaching methodologies should be taken up to make the subject of Pathology more clear and thoughtprovoking. ${ }^{3}$ Eighty-four out of ninety (93\%) 
students participated in the study while in a study done by Quadri et $a^{5} 56 \%$ of the students filled the questionnaire and another analysis done by Anand et $\mathrm{al}^{6}$ showed $99 \%$ response rate.

Student's feedback has been recognized to be a significant method in analyzing and determining productiveness of instructional strategies and assessment methods in medical education. ${ }^{7}$

In the present study, $64.42 \%$ of the respondents found the subject of Pathology interesting and 70.8 percent of the learners had the opinion that insight of Pathology will be helpful in clinical postings. In comparison to this a study done by Amar et $\mathrm{al}^{8}$ showed the percentages to be $68.5 \%$ and $86.6 \%$ respectively.

To enhance learning, the content of lectures should be structured and it should include narrations and images relevant to the topics. ${ }^{9}$ With respect to the content of the subject, $48.42 \%$ of the students were satisfied with the clinical correspondence and $42.46 \%$ with the content of the lectures. In another study, $41.62 \%$ learners found clinical correlation satisfactory and $36.30 \%$ were contented with the lecture content while Anand et $\mathrm{al}^{6}$ in their study found that only $35 \%$ students were satisfied with the content of the lectures.

This has been determined that in order to generate understanding, the lectures should be well-presented with stimulation of interest in the subject. ${ }^{10}$ In our study $56.5 \%$ students gave the feedback that important points were highlighted properly as compared to the findings of study by Quadri et $\mathrm{al}^{5}$ in which $53.8 \%$ of the students felt that important points of the subject were highlighted. Majority of the students in this study (52.5\%) were satisfied with the explanation given to clarify the subject contents but in the study by Anand et $\mathrm{al}^{6}$, the methods of explanation were stated to be satisfactory only by $35 \%$ students. As regard to the readability and usefulness of the lecture presentation $54.62 \%$ and $52.54 \%$ students respectively were satisfied in comparison with the percentages of $45.68 \%$ and $54.82 \%$ students in the study by Quadri et al. ${ }^{5}$
In our study mode of lecture did not show any association with students' satisfaction. However, in comparison to this $60 \%$ of the students agreed that didactic lecture is a constructive teaching learning approach and as regarding power point presentations $85.8 \%$ students thought them to be sufficiently good in study by Amar et al. ${ }^{8}$

Duration and number of lectures were found to be adequate by $68.06 \%$ and $72.54 \%$ of the students respectively. Quadri et al ${ }^{5}$ also showed that majority of the students believed that the number and duration of lectures was adequate. In our study, students suggested group based discussion, case based studies and integrated approaches can improve learning and teaching.

The assessment mode that is approved by students is related not only to their preferred educational circumstances but it also depicts their approach towards means of learning which subsequently influence their academic accomplishments. ${ }^{11}$

So the learners should be considered for their favored method of assessment as this will help to understand the factors which direct the process of learning. In this study nearly equal percentages of students were in favor of written exam and viva voce. In contrast to this, viva voce was shown to be the least preferred assessment mode in a study conducted on BDS students as the students fear to face the examiner. ${ }^{12}$

\section{LIMITATION}

The study was conducted at a single medical college limits generalizability of study.

\section{CONCLUSION}

A moderately high satisfaction was found among medical students regarding teaching and learning methodology of pathology. Pathology teaching system could be improved by applying group discussion; case based studies and integrated teaching approaches in our teaching system. 


\section{REFERENCES}

1. Sayyah M, Shirbandi K, Saki-Malehi A, Rahim F. Use of a problem-based learning teaching model for undergraduate medical and nursing education: $A$ systematic review and meta-analysis. Med Educ Pract. 2017; 8:691-700.

2. Sander T, Gotlieb Al. Topics include: The pathologist in patient care. Clin Pathol J. 2018; 12(2):123-25.

3. Bhosale U, Yadav G, Yegnanarayan R. Attitude, perceptions and feedback of second year medical students on teaching-learning methodology and evaluation methods in pharmacology: A questionnaire-based study. Nig Medi J. 2013; 54(1):33.

4. Marshall R, Cartwright N, Mattick K. Teaching and learning pathology: A critical review of the English literature. Med Educ. 2004; 38(3):302-13.

5. Quadri SSS, Srujana S, Mahesh S, Bheeshma B. Undergraduate medical students' feedback and perceptions on teaching learning methodology in Pathology at Government Medical College. 2016; 12(2):31-6.
6. Anand MK, Lakhani CJ, Javia MD. The role of medical students' feedback in undergraduate gross anatomy teaching. Anatomy. 2015; 31(4): 110-14.

7. Simpson PM, Siguaw JA. Student evaluations of teaching: An exploratory study of the faculty response. J Mark Educ. 2005; 22(3):199-213.

8. Shah AR, Shethwala ND, Parmar BH. Amar R Shah, et al. Perceptions of undergraduate medical students towards pathology. J Path. 2014; 17(3):12-18.

9. Dee Fink L. Editorial. New Dir Teach Learn. 2009; (119):1-7.

10. Dukhan S, Brenner E, Cameron A. The influence of lecturers' expectations of students' role in meaning making on the nature of their PowerPoint slides and the quality of students' note-making: A first-year biology class context. African J Res Math Sci Technol Educ. 2019; 23(1):100-10.

11. Struyven K, Dochy F, Janssens S. Students' perceptions about evaluation and assessment in higher education: A review. Assess Eval High Educ. 2005; 30(4):325-41.

12. Awan DU, Ahsan DU. Assessment; Is viva acceptable? Prof Med J. 2016; 23(02):213-6.

\begin{tabular}{|c|l|l|l|}
\hline \multicolumn{3}{|c|}{ AUTHORSHIP AND CONTRIBUTION DECLARATION } \\
\hline No. & \multicolumn{1}{|c|}{ Author(s) Full Name } & Contribution to the paper & Author(s) Signature \\
\hline 1 & Nabeela Naeem & Author & \\
\hline 2 & Shahid Jamal & Revision of work critically. \\
\hline 3 & Shameela Majeed & Drafting the work. \\
\hline 5 & Rabiah Asghar & Author & \\
\hline 6 & Amat-ul-Naval Talha & Drafting the work. & \\
\hline
\end{tabular}

